University of Wollongong

Research Online

Faculty of Education - Papers (Archive)

Faculty of Arts, Social Sciences \& Humanities

2012

\title{
Health imperatives in primary schools across three countries: Intersections of class, culture and subjectivity
}

Jan Wright

University of Wollongong, jwright@uow.edu.au

Lisette Burrows

University of Otago

Emma Rich

University of Bath

Follow this and additional works at: https://ro.uow.edu.au/edupapers

Part of the Education Commons

\section{Recommended Citation}

Wright, Jan; Burrows, Lisette; and Rich, Emma: Health imperatives in primary schools across three countries: Intersections of class, culture and subjectivity 2012.

https://ro.uow.edu.au/edupapers/1225

Research Online is the open access institutional repository for the University of Wollongong. For further information contact the UOW Library: research-pubs@uow.edu.au 


\title{
Health imperatives in primary schools across three countries: Intersections of class, culture and subjectivity
}

\author{
Jan Wright, ${ }^{a *}$ Lisette Burrows, ${ }^{b}$ and Emma Rich ${ }^{c}$ \\ ${ }^{a}$ University of Wollongong, Australia, ${ }^{b}$ University of Otago, New Zealand, ${ }^{c}$ University \\ of Bath, UK
}

In this paper we want to focus on the impact of the new health imperatives on young children attending primary schools because the evidence from both our own and others work suggests that younger and younger children are talking in very negative and disturbing ways about themselves and their bodies. We see this in a context where in the name of getting in early, governments and authorities are targeting primary schools and primary school parents and children for messages about health and weight. Just as 'obesity' has become a global concern, we argue that globalisation of risk discourses and the individualisation of risk, the league table on which country is becoming the fattest have impacted on government policies, interventions, schools and children which have much in common. In this paper then we argue first, that there is a problem (it is not one of children becoming fatter, but rather the way in which the ideas associated with the obesity crisis are being taken up by many children), and second, that the ways in which these ideas are taken up are not uniform across or within countries but depends on contexts - national contexts including but not only government policies and campaigns and within countries varies with social and cultural demographics of schools, in ways that are similar across countries.

Keywords: health, primary school children, social class, obesity

\footnotetext{
* Faculty of Education, University of Wollongong, Wollongong, NSW 2522, Australia. Email: jwright@uow.edu.au
} 
I think there is a lot of pressure on yourself and thinking that your health and your future could all be depending on what you eat now. It is scary sort of, like .... (Maddie, Year 5, St Mark's Primary School)

It is not new that young people's relationships with their bodies is often troubled (see for example, Birbeck \& Drummond, 2005; Burrows, Wright, \& Jungersen-Smith, 2002; Evans, Rich, Davies, \& Allwood, 2008; McShurry, 2009 Not in references). This, however, is not the discourse that is taken up in government policies and health campaigns where there seems to be a singular lack of interest in how bodies are experienced and imagined from the point of young people themselves. Rather policy and campaigns are formulated in the context of a deficit idea of young people who are at risk to themselves and to the state because of their ungoverned/unruly behaviours and bodies (Evans, Evans, \& Rich, 2002). A ubiquitous discourse that covers both children and young people is that of the 'obesity crisis' - that is, children and young people are at risk because of their increasing weight caused by sedentary behaviour and poor eating habits (Gard, 2008; Gard \& Wright, 2001). In this paper we focus on the impact of this discourse, and what we call the health imperatives that flow from it, on young children attending primary schools in three countries - New Zealand, United Kingdom, and Australia. The evidence from both our own and others' work suggests that younger and younger children are talking in very negative and disturbing ways about themselves and their bodies (Burrows, 2010 Not in refs; Burrows et al., 2002; Hutchinson \& Calland 20012011 in refs).

Public concern over an 'obesity epidemic' has been manufactured and refracted in the media and politics of most western and increasingly non-western countries. Indeed, we argue that globalisation of risk discourses and the individualisation of risk, reflected for example in obesity league tables which claim to show which country is becoming the fattest (see Hope \& Gardiner, 2010, as one example of many), have impacted on government policies, interventions, schools and children across many nation states and in ways which have much in common. In this paper then, we argue, first, that there is a problem - and that it is not one of children becoming fatter, but rather the way in which the ideas associated with the obesity crisis are being manufactured and taken up by many children; and second, that the ways in which these ideas are interpreted and enacted is not uniform across countries, nor within countries, but rather depends on contexts. It depends on their 'emplacement' in social and cultural contexts of schools and families as well as government policies and campaigns and on children's subjectivities, that is, the shape and appearance of their bodies and how they make sense of this.

Shilling (2010) suggests that in investigating the relevance of education to the ways ideas about bodies have been taken up in schools in the west there are two key issues to be addressed. The first is 'how we are to understand whether and how trends and processes external to the individual actually exert an influence on people's views, feelings, dispositions and actions' (page ?). The second issue raises questions about 'how broad societal developments actually get translated into specific institutions via policies, messages and practices' (pp. 155-156). While we touch on the second issue in this paper, it is the first with which we most engage: how have messages about health influenced views, feelings and dispositions of the children in the primary schools in our studies, and to a lesser extent their actions? This is not an easy task because dispositions cannot simply be understood as produced by school policies and programmes, or read from what teachers say and do with students (in their classrooms and elsewhere), or necessarily read from what students say and say they do. To be able to say something of substance about how social facts (including ideas) about 
health becomes part of someone's embodied experience, and requires a more extended engagement with children in different contexts. However, what we can do in this paper is examine how a large number of primary school children talk about health, and particularly the relationship between their talk and the meanings and practices associated with health in their specific school.

In addition, by looking more closely at two transcription texts produced from interviews with children from schools with very different social and cultural locations, we can say something about how the children's talk about health and their bodies is relational in a very personal way; it is related to the intersection of the child's experience of their body with family relations, which in turn are shaped by the wider social and cultural context. This demonstrates both the predictability on some counts and the unpredictability on others of how children make sense of health messages and how they take these up. It demonstrates how their subjectivities, shaped by and through their many interactions with other people, texts and practices, influence the ways they make sense of their bodies and interpolate themselves into health and body discourses and practices.

\section{Social class, health and the body}

Our analysis suggests that social class as a concept does not travel easily across countries. As Stephen Ball (2006) writes: 'class is not the same everywhere ... class meanings are inflected by culture and place' (p. 7). In the education literature in the UK and Australia, there has been a long tradition of explaining class inequalities in terms of disadvantage, influenced by neo-Marxist writing about the working and middle classes. More recently those writing in the area of social class in education have drawn on Bourdieu and for some others, particularly in the UK on Bernstein (for example, Evans \& Davies, 2008). There has, however, been less attention to the intersection of race, ethnicity and social class. In New Zealand, in contrast, the starting point is often race in conjunction with the social and economic position of Maori and Pacifika peoples in New Zealand society (see, for example, Durie, 2005).

Although recent analyses have focused on 'income differentials' as precursors of 'health' (Germov, 20052009 in refs; Pickett, et al., 2005), in much of the mainstream health/health promotion research, social class often functions as the primary social determinant of health inequalities and healthcare disparities. However, this is often translated (rather reductively) into policy and popular consciousness through the media as the consequence of inappropriate (for example, single parent) family structures. Children's and families' choices are talked about primarily in terms of deficit; families purportedly do not know enough or do not care enough to educate children about appropriate food choices and exercise levels. Having nurtured the view that families/guardians do not take their responsibility seriously, schools and government agencies are then invoked as means of addressing the deficit through intervention. As Walkerdine (2009) writes, commenting on a chapter in the Biopolitics of the Obesity Epidemic:

Poor people, [Murray] tells us, are thought not to make the right choices and so those have to be made for them. This presents us with the centrality of different modes of regulation for class and poverty, race and ethnicity, fat and thin. The already pathologized subject is not treated in the same way at all as a responsive and responsible subject (2009, p. 202). 
Despite the many criticisms of social class analyses (Ball, 2006), we do not want to eschew a class analysis because it is difficult; rather, we want - following Compton (quoted in Ball, 2006, p. 6) - to explore 'a more flexible approach', one which takes into account demographics but which, like Evans and Davies (2008) sees social class (and we would add culture) as experienced in and by bodies often in very subtle but 'visceral' ways that cannot be simply correlated with, or explained by, demographics. The study described in this paper was thus not so much interested in documenting health inequalities per se, but exploring the relationship between social class and culture and children's subjectivities. So while we ask whether the differences we see in how the children in the study talk about health and their bodies can in any way be explained in terms of social class and culture, we also ask what else beyond these categories. Following Butler (2004), we assume their subjectivities are not determined by, but are constituted in relation to, and also formed in excess of the categories of social class and culture; and not limited to singular positions in relation to health discourses.

\section{Methodology}

The data we draw on for this paper comes from a number of funded projects all investigating the impact of the policies and strategies associated with the obesity epidemic on schools and students. The study involved data collection in primary and secondary schools in New Zealand, United Kingdom, and Australia. The schools in the study were selected first on the basis of social class demographics and second on the basis of ethnic diversity, with the intention of studying how social class and culture might have been implicated in the ways schools across the three countries recontextualised popular, scientific and institutional meanings of health, and how social class might also be implicated in ways in which the children took up these ideas. In this paper only the data collected in the primary schools, specifically from children between 9 and 11 years of age, has been used. While the focus will be on the analysis of the interview data with the children in the schools, teacher interviews, field notes and documents collected from each school have also been used to provide context.

There were eight primary schools in total across the studies, three in the UK, two in New Zealand and three in Australia. In each school, between 10 and 12 boys and girls were interviewed in pairs $(n=94)$. The interviews in New Zealand and Australia used the same schedule of interview questions as their starting point; children's responses in the UK interviews were prompted by a set of cards with the words, 'obesity', 'body', 'school', and 'health'. All interviews were as conversational as possible with the interviewers working with the children's answers to help them elaborate on their meanings of health, the body and obesity. The interviews were all coded in QSR Nvivo. However, for this paper while the various nodes have been used as a guide, all of the interviews from the three countries were read again closely by the first author to better understand responses in the context of the interview as a whole. This reading prompted the selection of two interview texts for a closer reading to answer the question: how were the children's subjectivities constituted in their talk and what could be made of the relational aspects of families, culture and social class?

\section{The policy and syllabus context}


In the last ten years in the UK, New Zealand and Australia, the concern over what has been seen as increasing levels of childhood obesity have prompted government health campaigns and the funding of school-based initiatives in each country to avert the putative disaster. However, in New Zealand the election of a Conservative government, and in the UK a Conservative/Liberal coalition motivated by more libertarian and individualist ideologies, has resulted in a shift away from what have been seen as 'nanny state' interventions, spending government funds on health promotion and social marketing programs to a marketization agenda where the expectation is that 'young people ... become more entrepreneurial and competitive' (Roberts, 2003, p. 498). Some of the programs which were in schools at the time of the data collection, for example, the six million dollar 'Mission-On' programme, regulatory requirements for schools to sell only 'healthy food' in canteens, youth web-sites set up to encourage more exercise and healthy eating have all been abandoned on the argument that the prior government was interfering in ordinary New Zealanders' lives. In the UK there have been similar reallocations of funding with cutbacks in projects such as the Change4Life campaign. At the time of data collection, however, a health interventionist policy was still being promoted in both UK and New Zealand.

Australia and New Zealand have similar approaches to school health education through a health and physical education syllabus within the formal curriculum of the school. Both claim to make a contribution to the curriculum through a focus on the whole person and to be based on a broad notion of health 'that encompasses all aspects of an individual's wellbeing, inclusive of social, mental, physical and spiritual health' (NSW Department of Education and Training, 2007, p. 5). Providing children with the knowledge to 'make informed decisions related to health and physical activity and to develop attitudes towards a healthy lifestyle' are central ideas in both syllabi. Further, both syllabi, at least on paper, endeavour to consider health-related issues 'in context', recognising the ways broader familial, community and cultural locations influence the choices and capacities young people can enact in relation to 'health'. Health-related fitness is a main credo of the both New Zealand and Australian syllabuses. Although it is emphasised that 'participation in regular physical activity is more important and more achievable for students than physical fitness' (NSW Board of Studies, 1999, p. 14), the purpose of physical activity both now and in the child's future is explicitly for health benefits. Children should be taught movement skills so that they develop the competencies to maintain a healthy active lifestyle in the future.

In the UK, while Physical Education is a statutory and examinable subject (except in independent schools), Personal Social and Health Education (PSHE) is only a 'suggested element of the curriculum'. Penney and Harris (2002 Not in refs) contrast the UK National PE Curriculum to that of New Zealand, particularly in relation to 'health'. They argue that an emphasis on motor skill acquisition and sporting performance, marginalises any exploration of health issues and that health in this context becomes a 'desirable inevitable outcome of involvement in organised sport' (p. 107). This 'narrow conceptualisation of health' is contrasted with the New Zealand HPE curriculum within which 'social, cultural, environmental and, most notably, critical discourses are visible rather than excluded or subordinated' (p. 102). For the purposes of this paper, what the New Zealand and Australian HPE curricula include and the UK does not - is a specific component of a key learning area which focuses on health. While PSHE looks like becoming a statutory subject in UK schools in 
2011, it is currently optional and can be and is taught by a variety of teachers and in a variety ways. At the same time it should be acknowledged that the HPE in New Zealand and Australian primary schools is generally not taught by specialist teachers and the Health component, in particular, is often assimilated across other areas or taught by outside school agencies such as Life Education. Life Education resources focus predominantly on assisting children and young people to make 'good' health choices, to avoid 'risky' behaviours and to understand how their 'bodies' work (Life Education Australia, 2010). While programmes like these share some of the intent of formal syllabi, the 'critical enquiry' emphasis of contemporary HPE syllabi is notably absent. What is common across many of the schools are intervention programs specifically targeting healthy eating and exercise. The catholic primary schools in the UK were associated with the national 'Healthy Schools Project', and all of the Australian schools had at some point taken up 'Munch and Crunch', 'Munch and Sip', and 'Jump Rope for Heart', and the New Zealand schools, 'Push Play' and 'Jump Jam’.

\section{The schools}

The primary schools to be discussed in this paper covered a range of demographics as indicated primarily by the populations of students on which they drew. In the UK, the two schools categorised as middle class were Fraser, a multicultural preparatory school and Westwood, a small catholic village school. The working class school was Rosehill, a large multi ethnic catholic school situated in an inner area of a major city with a large proportion of South East Asian immigrants. In Australia, population demographics and also indices of disadvantage (Australian Index of Relative SocioEconomic Disadvantage) were used in the selection of the schools. The middle class school was St Mark's, a small catholic school with children from Anglo-Australian parents in largely professional and managerial occupations. Somewhere in between was Trimdon, a state primary school with children from families in professional and trade occupations, many from European (Italian and Macedonian) backgrounds. The school categorised as working class was St Claire's, a small catholic school with similar ethnic demographic to Trimdon, but also including children from Pacifika families. In New Zealand, the middle class state school, Marivale, drew a student population primarily from Pakeha professional families. Toroa, in contrast, drew on a student population from Pacifika and Maori families, mostly in manual occupations. Labelling the schools in terms of social class was difficult, firstly because categorization is in and of itself problematic, but also pragmatically in the use of terms with middle and working class common in UK research, and low and high socio-economic status (SES) more common in Australian and New Zealand. We have chosen to use the terms working and middle class because these are more widely used in sociological and cultural analysis and because they, moreso than SES, capture the notion of habitus, or embodied dispositions that are 'constituted by a set of affectively loaded, social and economic relationships that are likely to strongly influence, if not determine and dominate, people’s lives’ (Evans \& Davies?, 2008, p. 200).

That schools are classed places is not disputed and was obvious in the ways the different schools approached the education of their children and the ways in which the teachers talked about the children. For example, Fraser, the primary preparatory school has particular children both in mind as its pupils and its graduates, and this is made quite explicit in school prospectuses and in the educational program at the 
school. The same could be said of the teachers at Toroa who have the welfare of their Maori and Pacifika children high on their agenda and whose education program reflects its high index of disadvantage in the New Zealand system.

Looking across all of the primary schools in the study, it has been much easier to demonstrate similarities in the middle class primary schools and the ways children from these schools have talked about health, weight, and their bodies. On the other hand, those schools which do not easily fall into the middle class category were much more difficult to talk about in any general way. For the three schools that might be classified as 'working class' schools, the neat divide between working class and middle class just did not hold as a way of explaining how ideas about health were drawn upon by the students. It has been clear from the interviews that children's circumstances speak to family relations that do not fit neatly into predictions of a social class demographics, but rather are complicated by culture, parents' aspirations for their children, their children's health, and the children's own experience of their bodies which are in turn socially and culturally mediated. The difficulty has also been to avoid the positioning of these schools as 'other' than middle class, because they do not fit into neat patterns of relations between school, home, and student meanings of health.

\section{The middle class schools}

At Fraser, the UK privately-funded multicultural preparatory school, students were encouraged to work hard academically and take part in a range of extra curricular activities. Health was strongly encouraged through a focus on sporting achievement, and health education was taught primarily through science, with some in PSHE. The teachers observed that overweight was not an issue at the school. From the perspective of the healthy schools coordinator, the role of the school was to guide and encourage the child, to prepare the child in ways which 'allow[s] them to have an active life, make sensible choices and be aware of things that they need to be aware of ... guidance on what you should eat, what you shouldn't eat, how much exercise you should do'.

Westwood, the small village school, took itself very seriously as a healthpromoting school with a whole school approach to health education. Health education was delivered formally and informally across various aspects of the school, including science and PSHE, assemblies, and via the school involvement in the government sponsored 'Healthy School' Program. The PE co-ordinator reported that 'parents take the healthy schools seriously - provide healthy snacks all the time'. She said an aim of the school was to produce happy healthy 'all-round good people'. Again, overweight was not seen as an issue for the children at Westwood. Like Fraser, health promotion was closely associated with sport and physical activity, and government funding was used to bring in outside agencies to provide 'quality PE', which seemed to be mostly about bringing the teaching of sports such netball, hockey, tennis, badminton, as well as dancing into the school.

At the New Zealand school, Marivale, health and physical education were taught to meet National Administration Guidelines requirements around the development of movement skills and 'the promotion of healthy food and nutrition for all students' (NZ Education, 2010). Teaching about food in Year 5 was associated with a unit on what makes good learning, 'we spend a little bit of time talking about what foods help us learn better' (Year 5/6 teacher). The teachers did not see children's weight as an 
issue for children at their school, and there was no real concern about the school policing the school food environment. Indeed the principal thought this would be difficult with school fund raising activities run by parents often taking the form of 'sausage sizzles' and chocolate sales.

The Australian school, St Mark's, was situated in an area well served by facilities, with a wide variety of community sports. The community was described by the principal as an 'active community' with the most of the children participating in sports and recreation activities outside the school. Although there seemed to be general agreement that there were few children who might be judged to be overweight or obese, 'I wouldn't have thought there'd be much of that (obesity) here, most of the kids seem pretty healthy and slim', the school had a very active healthy lifestyles agenda, promoted by one teacher, with health eating promoted through a 'Munch and Crunch' program, healthy canteen initiatives and 'Jump Rope for Heart'. The school also had a specialist physical education teacher shared with other schools including St Clare's.

\section{Working class schools}

Rosehill, an inner city multi-ethnic primary school in the UK, was situated in an area lacking facilities and spaces for play, so exercise and diet were seen as the main health priorities of the school. Because of the perceived poor low levels of parental responsibility towards children's activity and health, this school saw its role very clearly in terms of modelling correct behaviour through its staff, thus made concerted efforts towards this by facilitating a 'staff fat club' with staff weigh-ins and many others were members of weightwatchers. It also took a strong interventionist approach, adopting the view that the current health status of the students was assumed to have a future impact on their future lives and health. For example, children were no longer allowed to bring chocolate into school to celebrate a child's birthday, but instead were invited to 'bring a book for birthday rather than a box of sweets' (Healthy Schools co-ordinator). Children's diets were also monitored through lunch box inspections, and on occasions parents were contacted when lunch boxes were deemed to be 'just junk'. PE lessons involved heart rate measurements and students were encouraged to take part in a variety of sports despite not having their own sports field. External organisations were also brought into the school to deliver health education.

Children at Toroa primary school in New Zealand came typically from families where the adults had low paid jobs and lived predominantly in government housing. Toroa was something of a poster-school for health promotion agencies, having achieved Gold status in the national healthy school awards delivered by New Zealand's Heart Foundation. It was inundated with policies and programmes focused on improving its children's health, its walls were graced with numerous posters promoting healthy food and physical activity, and pride of place was its Health Promoting School trophy. The Education Review Office, an institution that examines the functioning of all schools in New Zealand, consistently reports Toroa as a school with a caring, whanau-style feeling and ethos (see also Burrow's paper in this Special Issue).

Like Toroa, St Claire's primary school in Australia celebrated diversity and placed a greater emphasis on social relations and community than on individual health behaviours. This is not to say that some of the teachers did not express a concern for 
the children's health in relation to their weight, nor that the school did not teach about 'healthy foods' and healthy behaviours, although this was mostly from the Life Education Unit. This however was not a prevailing theme in the school. The school had limited facilities for physical activity; it had a very small playground made smaller at the time of the study by its becoming a building site. The children were also being weighed for another health project.

Trimdon state primary school, sat somewhere between St Mark's and St Claire's in terms of demographics and SEIFA and this is reflected in the students' responses. The school took seriously its commitment to multiculturalism and was also involved in an environmental initiative. The school was committed to encouraging children to participate in physical activity through offering a variety of sports. Teachers at the school did express a concern about the unhealthy food that came to school in lunch boxes, and saw overweight as an issue for a significant number of children at the school. The school used Life Education for health education and there were no obvious health intervention programs at the school, beyond 'Munch and Crunch' for children in the early years.

\section{What do the children have to say about health?}

Across all countries and schools, the most likely first response, and the one most extensively elaborated, to questions of meanings about health was the connection between health and eating well and doing enough physical activity/exercise. Ideas promoted in the schools and in policy were 'well known' by the children - they made the appropriate and valued connections between physical activity, food intake and health. They separated food into good food (fruit and vegetables for the most part rarely meat) and bad food/junk food (chocolate was high on the list and other foods that are regarded as high in sugar and fat). These simple associations were like a mantra. When asked about their own health, their evaluation generally mentioned their appearance, their level of fitness, or their behaviour - eating or not eating the right foods and getting enough exercise. Although the children at the two working class schools in New Zealand and Australia came eventually to talk about health in these terms, their first responses were often less 'informed' and more personal. Reflecting some minor distinctions, New Zealand children also mentioned drinking lots of water and habits of hygiene that seems to have been part of the health messages to which they had been exposed. The following responses from Stacey and Jane (at Trimdon) have all of the elements common in so many of the answers.

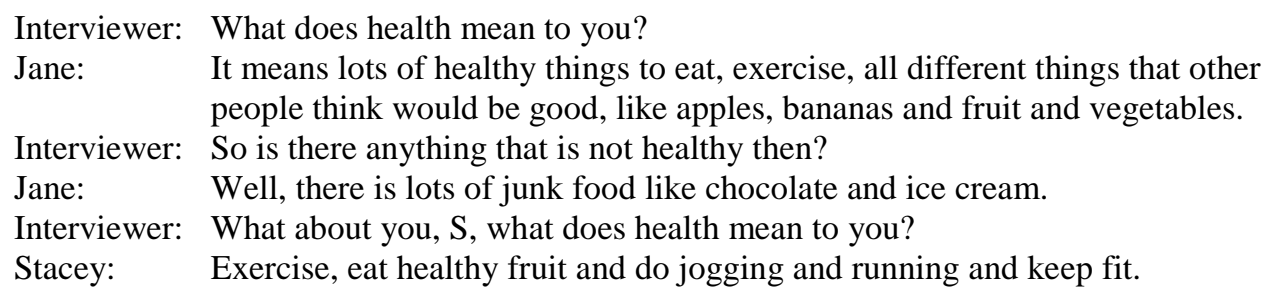

These shared understandings in Australian, New Zealand and UK schools reflect the similarities in government run campaigns, a similar syllabus, similar parental preoccupations and the influence of the Life Education in New Zealand and Australia.

Talk about health often moved on to talk about weight or appearance. Many of the children understood health as a three-pronged relationship between eating, exercise, 
and weight/shape. For many, this relationship was deterministic - what a person eats and how they exercise determines their weight/shape, which in turn determines their health. For most the problem was about overweight but other discourses have also had an impact with some children talking about the undesirability of being too thin.

Children at Fraser in the UK reported undertaking various regulative practices to monitor their own weight, for example weighing themselves and using pedometers regularly. For example, in the following exchange Miele talks about personal behaviour in relation to managing her own weight.

$\begin{array}{ll}\text { Miele: } & \text { Eat good food and exercise everyday 'cause it will burn off your carbs and make } \\ & \text { you fitter. } \\ \text { Interviewer: } & \text { Why do you think you do those activities and try to eat healthily like you do? } \\ & \text { What are the main reasons? } \\ \text { Miele: } & \text { Well, I don't want to be fat. I don't want to be thin either, I just want to be } \\ & \text { average size [...] I’ve lost quite a lot of weight since I've been eating my } \\ & \text { bananas and everything and doing my dancing. } \\ \text { Interviewer: } & \text { How do you feel about that? } \\ \text { Miele: } & \text { I feel really happy with myself because I've gone on a bit of a diet. This } \\ & \text { morning I didn't have any breakfast [... I've got one on my bike. It tells me } \\ & \text { how many meters I've done in a day and when I clip it onto my belt it will tell } \\ & \text { me how many steps I’ve done in a day [...] I just want to know if I need to do } \\ & \text { more. I try to improve it, so say if I've done fifty in a day I'd do like seventy, } \\ \text { and it also tells me how many carbs you've burnt off and how many stones } & \\ & \text { you've lost. }\end{array}$

And from Aisha at Marivale in New Zealand,

Interviewer: Yeah, how do you know these things, who’s taught you about weight and shape, where have you heard about that sort of thing?

Aisha: $\quad$ My parents.

Interviewer: Ahh, your parents, OK.

Aisha: They worry about it all the time?

Interviewer: Do they?

Aisha: $\quad$ Yes.

Interviewer: What do they worry about?

Aisha: $\quad$ Like overweight and like looking big and yeah.

Interviewer: So they're worried that you might be, or they worry about just generally?

Aisha: Generally.

Interviewer: Yeah so they talk about it lots?

Aisha: Yeah.

The preoccupation with weight, and particularly with being thin that was evident for some of the children at the middle class schools (but less promoted by their schools) was also evident in how the children at Rosehill talked about weight. The strong health imperatives at this UK working class school were evident in children's concerns about their changing weight and body shapes and all those interviewed reported engaging in practices of surveillance such as regularly checking their weight. Many of the students drew on emotive language when describing how fearful they were of becoming obese, for example Dinesh said that he 'bad dreams about becoming obese', and Mark: 'Like a stage of growing and sometimes I'm scared what's gonna happen'. These fears drew on projected ideas about what life would be like in (a not so distant) future when, if they were to put on weight, they would be bullied, unable to move, lazy and no longer able to play sport.

The fear of putting on weight in the future was particularly the case for the middle class children for whom, healthy eating and exercise were not issues that they saw or 
their schools saw as affecting them now. The threat of being overweight in the future, however, could be a potent source of anxiety. For example, Marnie's (St Mark's) response in the following quote was to a question about her sources of information about health:

I think that one of the biggest things that I get a big message I don't want to be overweight and stuff is when I go walking in the City and you see those people that are a bit overweight and I just don't want to end up being like that. (St Mark’s, female student)

And from Leon at Fraser in the UK in response to the question: 'Is there anything outside of school that makes you think about your body?'

\footnotetext{
Well, sometimes when you're walking down the streets, you sometimes see quite big people. Then you think would I want to look like them and you think like that, and you think about where they might go to eat and stuff and then you think that could be me, so you eat more healthily. (Fraser, Male student)
}

There was very little talk about weight at the two Australian working class schools, St Claire's and Trimdon. At Toroa, weight was spoken about from immediate experience, either in relation to families and the risk of illnesses such as diabetes or the students' own personal experience of being teased about their weight. Being heavy or bigger than they would like to be was a personal experience for some of these children, the boys as well as the girls. At the same time being skinny was just as much a problem. The children at St Claire's and Toroa were also likely to speak with much less certainty about health knowledge and to be less dogmatic and prescriptive about health behaviours. For example when Bo, from Toroa talked about his own health, he said that he was trying to get his 'health [weight] a little bit lower to try and make my size more um like skinnier yeah. Um so trying to eat like vegetables and healthy food that can help me ... 'cause my weight is like whooa big'. He was, however, much less clear about how he was going to do anything about this although he said he thinks about food a lot and sometimes does exercise and stretches. He said he learns about what to eat from TV but he also talked about how his mum, dad and sister were 'kind of getting bigger' which he was worried about and how his dad sometimes exercised on the 'Ab King Pro' they have at home.

When it came to specific questions about 'obesity', the children from the middle class schools were able to define it, linked the word with over-eating and insufficient exercise and in some cases with moral ideas such as laziness. We would suggest that for children in the middle class schools, knowledge about 'obesity' formed part of the formal knowledge taught in science, PSHE, and at Marivale from its status as a health 'project' topic. Knowledge about obesity thus became part of their knowledge about the world - there is an 'obesity epidemic', and children are getting more and more obese. However, obesity is not something with which they are personally familiar - it is not evident amongst the people they know, rather it is associated with those others who are less regulated in the ways they eat, who eat 'takeaways' and whose parents care less than their own. As Meile says:

They probably haven't raised their child healthy, 'cause some parents just let their children eat and eat and eat and if you eat and eat and eat you get a brain problem where your brain's just telling you to keep eating. (Fraser, female student) 
The children at Rosehill, Toroa and St Claire's were far less familiar with the technical term; most needed the term to be explained to them. This suggests that the schools did not directly use the ideas of the 'obesity epidemic' as a way of talking about children's health, but rather approached health in ways more associated with changing personal behaviour (see Burrows, in this Special Issue)

\section{Subjectivity as mediated by social class and culture}

This paper thus far has provided a general sense of how the children talked about health and bodies across the schools and countries with some indications of differences between schools. In this last section of the paper we want to use a closer analysis of interviews with children from two schools, the middle class school, St Mark's, and the working class school, Toroa, to trouble some of these generalisations. While a more extended engagement with the girls whose interviews are used below would help us say more about the relationship between their biographies and the way they talked about health and weight in their interviews, what they had to say provides some ways of understanding their subjectivities at the time of the interviews. This in turn points to the ways people engage with health ideas are not simply predictable from class and social position, although the interviews also show the ways in which these play out in the children's subjectivities. All of the girls in this section describe themselves as overweight and their subjective experience of their bodies, formed itself in relation to class and culture, impacts on how they responded to the questions about health and bodies.

\section{Mere}

The first of the children is Mere, a female student at Toroa in Year 5/6. She was interviewed with a friend Ani, however, it is Mere who does most of the talking in the interview. When asked about how she feels about her health, Mere responds she feels 'OK'; asked why, says 'I don't really eat that much junk, like most of the time we eat like, 'cause I have this calendar thingy and it shows what to eat like cheese, fish and yeah'. In what follows it becomes evident that the calendar provides information about what to eat and that she records on the calendar what she eats on a daily basis. It is something she does with her dad who 'tests' her to see if she is 'still ok' and then decides whether she needs something more or less. It is something that just she and her dad rather than her other siblings do together. Dad can also be cajoled into buying her treats such as a pie, something not allowed when her stricter stepmother is around. Mere later speaks about her stepmother, with whom she seems to have a difficult relationship. The meaning of the calendar for Mere seems to go well beyond the recording of food; it seems to be as much about a special activity shared with her father as with a concern to monitor her food intake.

At the same time, Mere's weight is a problem for her. When she and Ani are asked if they think very much about their shape and weight, the two respond:

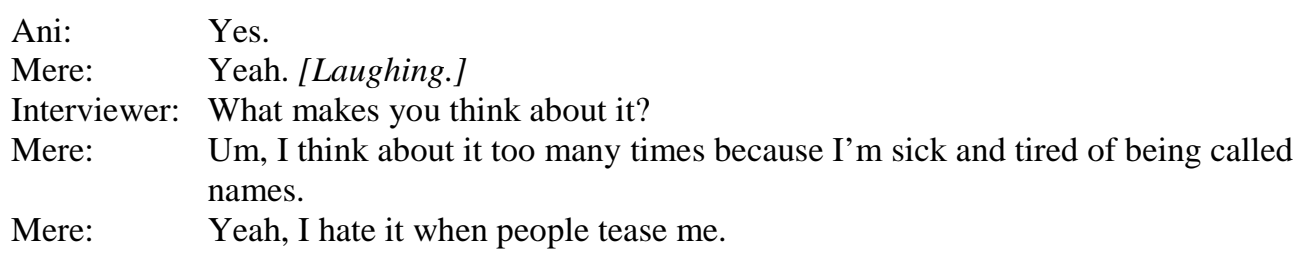


Interviewer: So does that happen at school?

Mere: $\quad$ Yeah a lot.

Mere described being called names by children at school, her cousins and being belittled by her stepmother. She and her friend also described how they feel they are judged because of what they eat.

Interviewer: Right, and what sorts of things is it that they're saying that make you annoyed? Mere: $\quad$ Ohh, stupid things, like I'd be like, ahh, you fat bastard, and like all that, ahh, look at you, shame, this person is much better than you. And then they will like list them. They say, see this is what you should eat, this is what you have got to eat this, and that.

Mere: $\quad$ And when like we order stuff, they say that we're eating bad, and that.

Ani: $\quad$ When we order.

Mere: $\quad$ When we order pies, and they'd be like, see no wonder why you're fat. See, man, you should start eating what I'm eating, if they're eating an apple or that.

Interviewer: So how does that make you feel then?

Ani: $\quad$ I feel really sad.

Mere: $\quad$ I feel really put down, like a put down.

Ani: $\quad$ I don't feel like coming to school anymore when people do that.

Mere: $\quad$ Yeah to me, I just want to go over there and you know start a fight.

She also described how she is judged by her stepmother:

Like she 'cause um like I'm saying like she doesn't know the inside of me like I can jog and you never know I might become thin. And on the outside she just judges us on the outside. She's like, ahh look, you fat thing. Man, if my daughters were here they'd show you what to do and then you could probably be like them. And she would tell me to go upstairs and bring her bag, and she brings a photo out of her daughter; she's very skinny like that, and I'm thinking, ohhhh.

After an exchange about how she copes with being teased about her weight, she says 'it hurts me inside' but then goes on to say: 'I don't care 'cause I'm happy with myself anyway ... Yeah I am happy to be the person who I am'

Mere talked about how she does try to lose weight: 'Once I tried [recording on the calendar] out I started to feel good about myself'. On one hand, it is clearly a constant struggle - knowing/wanting to eat 'healthy' - on the other hand, she loves the foods that she knows are likely to put on weight and derives considerable pleasure from eating these. When asked whether she and her friend eat anything that is unhealthy, they both laugh and say 'Yeah'. When prompted on what they like, Mere's answer is 'Pies, lollies, chocolate, fizzy drink'. When asked how she feels when she has it, she responds: 'I feel very good because like most of the time it's just healthy, healthy, healthy, that's all that's in my head, healthy, healthy, healthy. It's really good to get it out'.

In all of her talk about health, school barely gets a mention, despite the 'saturation of health messages' at Toroa. Her feelings about her weight seem to come more from the way other people make judgments about her and tease or bully her about it, than a visceral desire on her own part to be thin - indeed thinness is regarded as something you would want to avoid, it is not culturally desirable, it is to be like a 'broom stick' Her information about healthy eating comes from the calendar, some from television and some from her stepmother, though messages from school should not be discounted. What features most frequently in her interview are her relations with family - with her father who helps her with her calendar and buys her treats, her stepmother who judges her but with whom she also goes walking, and cousins who 
tease her. School rarely features except as a place where she is judged. Mere can't ignore her bigger body, but it is through her relations with others, whom she is in some ways able to dismiss, that she experiences her body as a 'problem'. These all get caught up in the relations of bodies, food and feelings about self. She does not interpolate herself into obesity discourses and seems generally able to resist being interpellated, although she recognises it when it happens - 'they judge me on what I buy from the canteen, what I eat'. She recognises the imperatives to eat 'healthy' food, but she also rejoices in treats and the food she likes; she is ready to take on those who would judge her; she does not accept their right to judge.

\section{Lisa and Kate}

The second mini-case is derived from an interview with Lisa and Kate, two Year 5 students (age 10) at St Mark's. Lisa's and Kate's interview was chosen because unlike the other children interviewed at their middle SES school, they describe themselves as 'big' and 'overweight'. Like the other boys and girls at their school, Lisa and Kate responded to the question about what health meant to them, with 'healthy eating, exercise' and 'keeping fit'. Kate's response to 'can you describe a healthy person' was with some giggling 'Well, someone who is not big', elaborating this with a gesture that described 'a big fat person'. When asked to add to their answer Kate says 'Well someone who is not big, someone who eats healthy. Lisa you have a go'. Lisa adds 'Like someone like that lady [walking by] who is walking and exercising and keeping fit'. When pushed a little further to elaborate 'are there other things that people might have or do in their life', Lisa responded 'Well maybe they are nice and bubbly and have a lot of energy and they have lots of self-esteem and like who they are.' When they were asked to rate their own health, Lisa say 'six or seven'. Her explanation for this is a good example of how many of the children at this and the other middle class schools talked about their family in relation to managing their health:

Because mum always gives me heaps (of) healthy things to do, and sometimes we walk to school and we go for bike rides with my dad, and we always eat healthy meals during the day or we get little treats, and sometimes we choose little chocolate bars from the cupboard.

However as the interview goes on, it becomes evident that Lisa and Kate regard themselves as 'big' girls, bigger than their 'tiny' peers. They have trouble fitting into dance costumes and they are teased about their size and feel 'out of place'.

Lisa: Well last year I was getting really, really big and all my clothes weren't fitting and then I tried them on and I had to go and get all new ones because I got really, really big. So I've been trying to get smaller but it's really not working so much now; it's not working. I used to be small, but now I just got big since I’ve been here.

It seems it is not so much that these girls are overweight but that they feel big in comparison:

Interviewer: Don't you guys think that maybe you are just growing a bit sooner than some of the other kids in your Year, or something.

Kate: $\quad$ Yeah, but all the other kids in the Year are really small.

Lisa: $\quad$ They are all like skinny [runts] so you walk next to someone.

Kate: $\quad$ And they are quite short. 
Lisa: $\quad$ Yeah they are all skinny.

Interviewer: And you feel quite big when you are around them because everybody else is really short.

Lisa: $\quad$ And you feel like you are out of place and you shouldn’t really be there with them if you are too big.

While it is not clear whether Lisa is overweight from any measurable perspective, from her perspective she is, and she stands out as being different:

Yeah, like here you really don't feel like you fit in because there's like tiny people, like I don't know one person in Year Five who is overweight that is a girl, except for me.

Kate is also trying to get smaller; they both find it hard work but at the same time refuse any feelings of guilt. Lisa for example declares at the end of this first exchange, with what seems like some pride or perhaps a challenge: 'Eating is my hobby'.

Kate: $\quad$ Yeah, like sometimes I try really hard, I go out for walks with my mum and then I try really hard at dancing.

Lisa: $\quad$ And then the next day you just go.

Kate: $\quad$ And then the next day I'm really tired and my shoulder blades hurt and I just couldn't be bothered to do anything else.

Lisa: $\quad$ So we sit in the lounge and eat.

Kate: $\quad$ Yeah, so you sit on the lounge.

Lisa: $\quad$ Eating is my hobby.

Later on in the interview when asked whether they get 'any information from TV about health?’ Lisa responds, perhaps provocatively:

Yeah, I watch TV twenty-four hours seven days a week when I'm not playing sport or at school, or I go on the computer and watch videos on You Tube, but I don't watch healthy eating ones.

Kate also takes what seems to be an irreverent attitude to health knowledge and injunctions to be healthy:

Yeah, we had to make this food pyramid and we were always talking about healthy stuff and our health and sometimes it gets really annoying. You are trying and like everyone is telling you, like Miss N is saying to be healthy at home and then Miss N will say to you 'if you guys aren’t healthy [... I I eat this today, I eat this today’ it makes you feel like you are not doing enough.

Because from Kate's perspective what is the point?

Kate: Well, yeah because like, well no, not really, people, like we bring to school like all the big people like me, we bring to school really healthy things and then all the little people are bringing to school like chocolate mousse and [...]

Lisa: $\quad$ Like chips and ...

Kate: $\quad$ And they are just eating it all around you and then they just stay as skinny as a little stick and if you ate that, whatever they ate, you would become ... [left unsaid]

And later in the same interview - 
Interviewer: It sounds like you guys take a fair bit of notice of what other people eat. Do you think people watch what other people eat in this school?

Lisa: $\quad$ Yeah, because you kind of feel like because one of my friends she eats healthy at school, because I went over to her house and she eats healthy at school and I think because she expected me to eat bad things because I'm big, she thought that I would normally eat chocolate freddo frogs and stuff but I don't. So at her house in the afternoon we have like, she asks if I want a chocolate freddo frog and she'll say 'yeah I want one' and then she asks again and I'm like no. But then she kind of expects me to.

On the one hand, there is considerable humour in the way Lisa and Kate talk about health messages, the strictures associated with being healthy - 'I watch TV 24/7', but at the same time they feel out of place and that they should eat less and exercise more in order to be 'smaller'. However, this seems an impossible task, because if you give in you could become 'like a ten tonne truck'. Lisa and Kate seem to have each other and a supportive family, they seem less troubled by this than some of the children that we cite above who may or may not be overweight but fear the risk. They refuse to be positioned as bad subjects, they refuse to feel guilty, at least in this interview. They recognise the discourse but refuse to be interpellated by it - 'I watch TV 24/7'; 'eating is my hobby'; they also recognise when others try to interpellate them - 'she [a friend] expected me to want to eat chocolate'. They reject the imperatives to monitor themselves, to stick to the kind of regimes that would lose weight, first, because they don't seem to work anyway, second, it is unfair (skinny people can eat what they like), and third, it is no fun.

In both these cases, the children's physical bodies, their size in particular, shape how they engage with the ideas about health and the body. There is, however, no neutral body - in both cases the way the children make sense of their bodies is mediated by class, culture and probably gender, although this is not pursued in this paper. Bodies can only be talked about and we would argue interpreted by their owners through language. Bodily feelings and emotional responses once brought into language become socially constituted: the big body is not in itself a source of shame; it only becomes so when others see it as shameful, whether these are others close to the child (who themselves are drawing on discourses to make this judgment); or messages from the media (which provide the means to evaluate the body and instructions in how one should feel about it). Mere and Lisa and Kate come to understand their bodies in the context of these social messages but also through material circumstances. Lisa and Kate tower over their peers. How they interpret this, however, is social; if they were boys this would perhaps be a good thing; but for girls they are 'out of place'. Their largeness is further interpreted in terms of discourse of overweight and instructions of how to avoid it or to lose weight.

There does however seem to be a qualitative difference between the ways Lisa and Kate and Mere live with imperatives associated with health and the body which we argue are at least in part associated with social class and culture. Our readings of Lisa's and Kate's transcript prompted a chuckle, Mere's prompted feelings of sadness. Lisa and Kate seem able to directly take on what others have described as a neo-liberal discourse of self-management (Vander Schee, 2008); one that requires them to act in disciplined/self-disciplining ways in relation to food and activity. They make an object of the discourse and use humour to distance themselves and their own enjoyment of life from its injunctions. They do this from a position where they seem to be secure in a family environment that provides 'heaps of' healthy food and where physical activity is part of their family life. Mere, on the other hand, seems much 
more vulnerable. Her feelings about her body are inexorably intertwined with her family and peer relationships, most of which do not make her feel good about her bigger body. Although 'healthy, healthy is in her head', her everyday life makes it difficult to put this into practice. She does not have the ordered life which supports Lisa and Kate; rather, her relationships and material circumstances leave her vulnerable to feelings of shame and self-hate.

\section{Conclusion}

For all of the children in the study, across the three countries, the ways they engaged with health messages was always and inevitably mediated by body shape and size (that is, by the sense of their own corporeality in time, place and space) and importantly by class, culture and gender. They were also mediated by family relations and by the ways schools took up and transacted health imperatives, which were themselves mediated by class and culture. The extent to which many of these messages were congruent with each other, was evident in the certainty and the consistency with which the children talked about health as related to eating 'good' food (fruit and vegetables) and exercising. This also points to the ubiquity of the obesity discourse and its related translation into policy, media and school syllabuses and practices in the UK, Australia and New Zealand (and comparable countries).

On the other hand, the children's talk about weight and obesity we would argue was rather different for the children from the middle class schools as compared to the working class schools, particularly where schools had taken up the project of the health promoting school. For the middle class schools, the teachers and the children within those schools, obesity was associated with those 'others', the children who ate takeaway foods and whose parents did not care enough - a coding for children from home unlike their own, working class children. While the children at the middle class schools might learn about 'obesity', this was not directed at changing the children at these schools, where obesity was 'not a problem'. While these were often experts in healthy behaviours, their anxieties about eating were more likely to be about avoiding becoming like those abhorrent 'others'; this in turn required a close monitoring of their own behaviour. Some of these children were already engaging in self-regulating behaviours, monitoring their diets, in a context where they were assisted by parents, had ready access to 'healthy' foods and dispositions in part formed by a fear of becoming/looking like 'those others'.

In those working class schools in which health promotion was taken to be part of the school's mission, the children were constituted as both the subject of obesity discourse and the target of behaviour change strategies. These children were understood to be directly at risk of becoming overweight and intervention was required to prevent this. For some of these children, these messages created anxieties in contexts over which they did not always have control, over choices about food and access to physical activity, the constant message to be 'healthy healthy healthy' when their material and social circumstances made it difficult to comply. In this way we argue schools and teachers recontextualised obesity discourses in ways which maintained those hierarchies which are implicit in the discourse itself - hierarchies which link the material bases of children's lives to potential and imagined futures. For the children in these schools, health was clearly associated with weight, because this is what they have been taught, but for young people like Mere, while they feel bad about being fat, they also seem to feel that this is not within their control. 
Our purpose in this paper has been to suggest through examples some relationships between social class, culture, schooling, and the ways children talk about and experience health, weight and their bodies. In doing so we hope we have avoided pathologising those children and their parents who do not comply either through their behaviour or their embodiment with morally loaded health imperatives around food and weight. We want also to argue that there are 'risks' in the obesity discourse and its associated imperatives for how children feel about themselves and their bodies; risks we suggest that are different for children of different social class and cultural locations. These are risks that schools and governments could well reflect on in developing policy, curriculum and interventions for schools and children.

\section{References}

Ball, S.J. (2006). The necessity and violence of theory. Discourse: Studies in the Cultural Politics of Education, 27(Issue?), 3-10.

Birbeck, D., \& Drummond, M. (2005). Interviewing, and listening to the voices of, very young children on body image and perceptions of self. Early Child Development and Care, 176, 579-596.

Burrows, L., Wright, J., \& Jungersen-Smith, J. (2002). ‘Measure your belly’: New Zealand children’s constructions of health and fitness. Journal of Teaching in Physical Education, 22(Issue?), 2938.

Butler, J. (2004). Changing the subject. In S. Salih, \& J. Butler (Eds.), The Judith Butler reader (pp. 325-356). Malden, USA: Blackwell.

Durie, M. (2005). Race and ethnicity in public policy: Does it work? Social Policy Journal of New Zealand, Volume? Issue 24, 1-11.

Evans, J., \& Davies, B. (2008). The poverty of theory: Class configurations in the discourse of Physical Education and Health (PEH). Physical Education and Sport Pedagogy, 13(Issue?), 199-213.

Evans, J., Evans, B., \& Rich, E. (2002). Eating disorders and comprehensive ideals. Forum for promoting 3-19 Comprehensive Education, 44(Issue?), 59-65.

Evans, J., Rich, E., Davies, B., \& Allwood, R. (2008). Education, disordered eating and obesity discourse: Fat fabrications. London: Routledge.

Gard, M. (2008). Producing little decision makers and goal setters in the age of the obesity crisis. Quest, 60(Issue?), 488-502.

Gard, M., \& Wright, J. (2001). Managing uncertainty: Obesity discourses and physical education in a risk society. Studies in Philosophy and Education, 20(Issue), 535-549.

Germov, J. (2009). Class, health inequality, and social justice. In J. Germov (Ed.), Second opinion: An introduction to health sociology, $4^{\text {th }}$ Edn. (pp. ??-??). Oxford: Oxford University Press.

Hope, J., \& Gardner, D. (2010). Now Britain is the fattest country in Europe (and the fifth most overweight in the world). Daily Mail, accessed 5 June 2011, http://www.dailymail.co.uk/ news/article-1314807/How-Britain-fattest-country-Europe-fifth-overweightworld.html\#ixzz1LFOOkGPp

Hutchinson, N. \& Calland, C. (2011). Body image in the primary school. London: Routledge.

Life Education Australia (2010). Primary school program. 17 April 2012 from

http://www.lifeeducation.org.au/what-we-do/our-program/13-primary-school-program McSharry, M. (2009). Schooled Bodies? Negotiating adolescent validation through press, peers and parents. Stoke on Trent: Trentham Books.

New South Wales Board of Studies (1999). PDHPE Syllabus: Principal's package. Available at http://k6.boardofstudies.nsw.edu.au/files/pdhpe/pdhpek6_principal.pdf 
New South Wales Department of Education and Training (2007). Personal Development Health and Physical Education K-6 Syllabus. Retrieved 28 July 2011 from http://k6.boardofstudies.nsw.edu.au/files/pdhpe/k6_pdhpe_syl.pdf

New Zealand Education (2010). National Administration Guidelines. Retrieved 28 July 2011 from http://www.minedu.govt.nz/NZEducation/EducationPolicies/Schools/PolicyAndStrategy/Plan ningReportingRelevantLegislationNEGSAndNAGS/TheNationalAdministrationGuidelinesN AGs.aspx

Pickett, K., Kelly, S., Brunner, E., Lobstein, T., \& Wilkinson, R.G. (2005). Wider income gaps, wider waistbands? An ecological study of obesity and income equality. Journal of Epidemiological Community Health, 59(Issue?), 670-674. No issue number

Roberts, P. (2003). Contemporary curriculum research in New Zealand. In W.F. Pinar (Ed.), International handbook of curriculum research (pp. 495-516). Mahwah, New Jersey: Lawrence Erlbaum Associates.

Shilling, C. (2010). Exploring the society-body-school nexus: Theoretical and methodological issues in the study of body pedagogics. Sport Education \& Society, 15(2), 151-168.

Vander Schee, C. (2008). The politics of health as a school-sponsored ethic: Foucault, neoliberalism, and the unhealthy employee. Educational Policy, 22(6), 854-874.

Walkerdine, V. (2009). Biopedagogy and beyond. In J. Wright, \& V. Harwood (Eds.) Biopolitics and the 'obesity epidemic' (pp. 199-209). London: Routledge. 